Original Article (short paper)

\title{
The role of body fat in the relationship of cardiorespiratory fitness with cardiovascular risk factors in Brazilian children
}

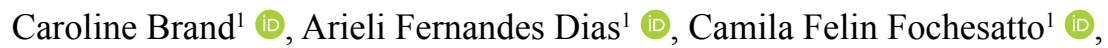

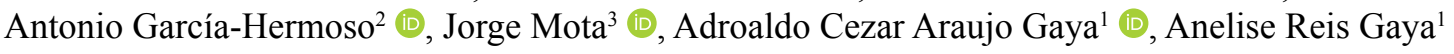 \\ ${ }^{1}$ Universidade Federal do Rio Grande do Sul, UFRGS, Project Sport Brazil, PROESP-Br, Post-graduation program in \\ Human Movement Sciences, School of Physical Education, Physiotherapy and Dance, Porto Alegre, Brazil; ${ }^{2}$ Universidade de \\ Santiago do Chile, USACH, Physical Activity, Sport and Health Sciences Laboratory, Faculty of Medical Sciences, Santiago, \\ Chile; ${ }^{3}$ Universidade do Porto, Research Centre on Physical Activity, Health and Leisure. Faculty of Sport, Porto, Portugal.
}

\begin{abstract}
Aims: To analyze the association between the percentage of body fat and cardiorespiratory fitness (CRF) with cardiovascular risk factors in children, and; to examine whether percentage of body fat acts as a mediator on the association between CRF and cardiovascular risk factor. Methods: This cross-sectional study included 128 children aged 7-11 years (Mean 8.54, SD: 1.42). The following variables were evaluated: the percentage of body fat, CRF, diastolic and systolic blood pressure, glucose, triglycerides (TG) and total cholesterol. For statistical analysis were performed Partial correlation and mediation analysis. All analysis was adjusted for sex, age and height. Results: CRF, the percentage of body fat, mean arterial pressure (MAP) and TG showed a correlation between each other. Percentage of body fat mediated the association between CRF and MAP (Indirect Effect= -0.008; IC: -0.0159 -0.0030), explaining $29 \%$ of this association. However, it was found that the percentage of body fat was not a mediator of the association between CRF and TG. Conclusion: The percentage of body fat mediates the association between CRF and MAP. Our findings show that the importance of a healthy body composition for the prevention of high blood pressure levels in childhood as well as the relevance of physical activity on these parameters.
\end{abstract}

Keywords: schoolers, health, arterial pressure, triglycerides

\section{Introduction}

The prevalence of cardiovascular disease (CVD) has been increasing all over the world ${ }^{1}$. Although, the presence of risk factors for CVD in children and adolescents has more clearly been identified over the last 20 years ${ }^{2}$. Initially, this kind of disease were considered a concern for the adult population, however studies have observed that many cardiometabolic abnormalities, including dyslipidemias, insulin resistance, and type 2 diabetes mellitus have its origin during childhood ${ }^{3}$. Thus, the early identification and intervention for children at risk of developing CVD would minimize the tracking of risk factors into adulthood ${ }^{4}$.

Cardiorespiratory fitness (CRF) has been considered an important health indicator ${ }^{5}$. Studies have shown that there is an association between low levels of cardiorespiratory fitness and CVD risk factors in children and adolescent ${ }^{6,7}$. Furthermore, it has been suggested that moderate to high levels of CRF could attenuate some of the adverse metabolic consequences related to obesity $^{8}$. Indeed, the general belief that normal weight is enough for being healthy could be wrong and it is now recognized that moderate to high levels of CRF plays an important role in health even for subject with body mass index (BMI) over $24.9 \mathrm{~kg} / \mathrm{m}^{2}$.

Therefore, studies have shown that both fatness and fitness are independently associated with cardiometabolic risk factors among youth. It has been reported that when adiposity is included in the models the magnitude of the association between fitness and cardiometabolic risk appears to be small to moderate ${ }^{9,10}$. Furthermore, a mediation analysis revealed that BMI has a powerful influence on the relationship between CRF and metabolic syndrome in schoolchildren ${ }^{11}$. The same kind of analysis indicated that BMI mediates the relationship between CRF and mean arterial pressure in Spanish schoolchildren ${ }^{12}$.

Although BMI, an anthropometric index, is widely used in epidemiological studies, it is unable to distinguish fat and lean mass ${ }^{13}$. Also, most studies have explored BMI as an intermediate and confounding variable in the relationship between CRF and cardiovascular risk factor ${ }^{11,12}$. Thus, considering percentage of body fat $(\% \mathrm{BF})$ could provide more precise information regarding adiposity influence on the association between CRF and CVD, the study aimed: 1) To analyze the association between percentage of body fat and CRF with cardiovascular risk factors in children; and 2) To examine whether percentage of body fat acts as a mediator on the association between CRF and cardiovascular risk factors.

\section{Methods}

Study design

This was a cross-sectional analysis using the baseline data from a longitudinal study that assessed the effects of a soccer intervention 
program on cognition-associated variables, metabolic syndrome and inflammatory markers in children. One hundred twenty-eight schoolchildren were included in this study (63 girls and 65 boys), aged 7-11 years, from a public school in the city of Porto AlegreBrazil, selected by convenience. All children in the first to fifth grade were invited to participate in this project. The parents from those who agreed to participate signed the consent form as well as the children signed the assent form. The Ethics and Research Committee of Federal University of Rio Grande do Sul approved the study (2014997). The research received support from CNPq process number 401969/2016-9/ Universal Announcement.

The minimum number of subjects in the sample was calculated through the software $\mathrm{G}^{*}$ Power version 3.1. For a sample calculation, an effect size $\mathrm{F}$ of 0.15 (medium effect, corresponding to 1.7 in prevalence ratio) was used, as well as the level of significance of 0.05 and a statistical power of 0.95 . Linear regression models have used with approximately five predictors and a 20\% increase to cover for possible losses and refusals. Based on these criteria, the minimum sample size was 107 children. The sample size was calculated for linear regression, considering that mediation analysis consists of different regressions. Thus, the sample size is sufficient for this analysis.

\section{Measurements procedures}

The variables were measured at school by trained researchers. Weight was measured using a digital anthropometric scale, graded from 0 to $150 \mathrm{~kg}$, with a resolution of $0,05 \mathrm{~kg}$. The children should be lightly dressed and without shoes. Height was measured using a metric tape fixed on the wall and extended from the bottom upwards, with the children kept in a vertical position, with feet and trunk leaning against the wall. The described procedures followed the PROESP-Br standard ${ }^{14}$.

CRF was assessed by running and walking test in six minutes $^{14,15}$. The evaluated ones should accomplish the greatest number of turns, running or walking, in a sports court with the perimeter marked with 6 cones and the ground with indications of meters traveled (from 4 in 4 to close 54 meters). The measurement of the test was noted from the number of laps traveled, plus the meters in the case of those who at the end of the time did not complete a lap, so after multiplying the number of laps by the perimeter of meters covered was obtained the estimate of CRF.

Diastolic and systolic blood pressure levels (DPB and SBP) were determined by an automatic blood pressure monitor (Omron Digital Hem-7130), using different sized cuffs according to the circumference of the right arm. The children must be sitting, at least 5 minutes rest, with the arm supported. Mean arterial pressure (MAP) was calculated using the following formula: $\mathrm{DBP}+[0.333 \times(\mathrm{SBP}-\mathrm{DBP})]$. We emphasize that a large number of published studies used MAP as an independent predictor of cardiovascular event ${ }^{12,16}$. Besides, adiposity is similarly associated with SBP, DBP and MAP, indicating that independently of the blood pressure component, children with more adiposity are more likely to have a higher risk of hypertension ${ }^{17,18}$.

After twelve hours of overnight fasting, capillary samples were collected. The fingertip was pierced using an automated lancet and the first drop of blood removed with a sterile cotton swab. This method was used because it allowed the dosage to be performed at school with fewer traumas and better acceptance between the children. Total cholesterol and triglycerides was determined by using Accutrend Plus, while glucose was evaluated by On Call Plus. Capillary samples was tested and authorized by Food and Drug Administration, and the coefficient of results variation (accuracy $>95 \%$ with an agreement of laboratory measures) are in according to the index established by National Cholesterol Education Program ${ }^{19}$.

Percentage of body fat was assessed using dual-energy X-ray absorptiometry Lunar Prodigy Primo (General Electric Healthcare; Madison, WI), by the same well-trained professional. This measurement was taken at the physical activity laboratory of Federal University of Rio Grande do Sul (Brazil).

\section{Statistical Analysis}

Descriptive analysis was expressed considering the mean and standard deviations of all variables included in the study. All variables were checked for normality. Independent Two-tailed T-tests were used to examine the sex differences. Considering that the variables, triglycerides, mean arterial pressure glucose and cholesterol, did not show differences between sexes, all the statistical analysis were performed with both sexes together to increase statistical power. Pearson correlation was used to determine the relationship between $\% \mathrm{BF}$ and CRF with cardiovascular risk factors.

To examine whether the association between CRF and TG and MAP was mediated by $\% \mathrm{BF}$, linear regression models were fitted using the PROCESS macro for the Statistical Package for Social Sciences (SPSS) version 24.0 (IBM Corp, Armonk, NY). The goal of this model was to investigate the total (c) and direct effects (a, $\left.b, c^{\prime}\right)$, reflected by the unstandardized regression coefficient and significance between the independent and dependent variables in each model. The model also investigated the indirect effect obtained from the product of coefficients $(a \times b)$, which indicates the change in the TG or MAP for every unit change in the CRF that is mediated by the proposed mediator (i.e. \%BF). The PROCESS macro used bootstrapping methods recommended by Preacher and Hayes $(2008)^{20}$ for testing mediation hypotheses, using a resampling procedure of 10.000 bootstrap samples. Point estimates and confidence intervals $(95 \%)$ were estimated for the indirect effect. The point estimate was considered significant when the confidence interval did not contain zero. Thus, the following criteria were used to establish mediation: (1) the independent variable $(\mathrm{CRF})$ is significantly related to the mediator $(\% \mathrm{BF})$; (2) the independent variable (CRF) is significantly related to the dependent variable (MAP and TG); (3) the mediator (\%BF ) is significantly related to the dependent variable (MAP and TG); and (4) the association between the independent and dependent variable is attenuated when the mediator is included in the regression model. The analysis was adjusted for age, sex and height.

All the analysis was carried out using the IBM SPSS 21 (SPSS, Inc., Chicago, Illinois, USA). The level of statistical significance was established at $\mathrm{p}<0.05$. 


\section{Results}

Table 1 presents the descriptive characteristics of the sample. The results indicated that there were differences in mean values of CRF and \%BF between girls and boys. Boys presented higher levels of CRF, while girls showed higher $\%$ in $\mathrm{BF}$.

Partial correlations between $\% \mathrm{BF}, \mathrm{CRF}$ and cardiovascular risk factors are presented in Table 2. MAP and TG were the variables that showed an association with $\% \mathrm{BF}$ and CRF. Also, there was an association between $\% \mathrm{BF}$ and total cholesterol.

When we tested the mediator role of $\% \mathrm{BF}$ in the association between CRF and MAP (Fig.1A), in the first regression equation, the association between $\mathrm{CRF}$ and $\% \mathrm{BF}$ was negative $(\mathrm{p}=0.01)$. In the second equation, $\mathrm{CRF}$ was also negatively associated with $\operatorname{MAP}(p=0.002)$. Finally, in the third equation, when $\% \mathrm{BF}$ and $\mathrm{CRF}$ were included simultaneously in the model, $\%$ BF was positively associated with MAP $(p<0.001)$ and associated negatively with CRF $(\mathrm{p}=0.01)$. Furthermore, the association between CRF and MAP was attenuated when \%BF was included in the model, indicating that $\% \mathrm{BF}$ a mediator of this association (Indirect Effect $=-0.008$; IC: $-0.0159-0.0030$ ), explaining $29 \%$ of this association. However, the analysis of the mediator role of \% $\mathrm{BF}$ in the association between $\mathrm{CRF}$ and TG (Fig. 1B), showed that $\% \mathrm{BF}$ is not a mediator of this association since the above-mentioned criteria for the mediation analysis was not observed.

Table 1. Characteristics of the study samples according to sex in children.

\begin{tabular}{|c|c|c|c|c|}
\hline & $\begin{array}{c}\text { Total } \\
\text { Mean (SD) }\end{array}$ & $\begin{array}{c}\text { Boys } \\
\text { Mean (SD) }\end{array}$ & $\begin{array}{c}\text { Girls } \\
\text { Mean (SD) } \\
\end{array}$ & $\mathbf{p}$ \\
\hline Age (years) & $8.82(7.89)$ & $8.36(1.51)$ & $8.43(1.44)$ & 0.39 \\
\hline Weight (kg) & $33.14(10.59)$ & $32.86(9.30$ & $33.45(11.83)$ & 0.74 \\
\hline Height (cm) & $1.34(0.10)$ & $1.34(0.09)$ & $1.33(1.11)$ & 0.21 \\
\hline Cardiorespiratory fitness (m) & $770.52(136.82)$ & $798.10(146.36)$ & $741.36(119.45)$ & $<0.001$ \\
\hline Percentage body fatness (\%) & $32.73(8.36)$ & $30.34(8.80)$ & $35.15(7.15)$ & $<0.001$ \\
\hline Systolic blood pressure (mmHg) & $103.49(11.56)$ & $103.40(11.35)$ & $104(11.82)$ & 0.62 \\
\hline Diastolic blood pressure (mmHg) & $60.75(8.83)$ & $60.78(9.13)$ & $69.28(9.28)$ & 0.29 \\
\hline Triglycerides (mg/dL) & $116.69(61.68)$ & $108.83(66.79)$ & $125.49(54.46)$ & 0.07 \\
\hline Glucose (mg/dL) & $86.01(7.46)$ & $86.19(7.23)$ & $85.78(7.79)$ & 0.69 \\
\hline Cholesterol (mg/dL) & $177.01(22.34)$ & $175.72(23.15)$ & $178.43(21.46)$ & 0.42 \\
\hline
\end{tabular}

SD: Standard deviation; $\mathrm{p} \leq 0.05$

Table 2. Partial correlation between body fat percentage and CRF with cardiovascular risk factors in children

\begin{tabular}{|c|c|c|c|c|}
\hline & \multicolumn{2}{|c|}{ Percentage of body fat } & \multicolumn{2}{|c|}{ Cardiorespiratory fitness } \\
\hline & $\mathbf{r}$ & $\mathbf{p}$ & $\mathbf{r}$ & $\mathbf{p}$ \\
\hline MAP & 0.38 & $<0.001$ & -0.45 & $<0.001$ \\
\hline TG & 0.31 & 0.004 & -0.31 & 0.005 \\
\hline Glucose & 0.06 & 0.56 & -0.09 & 0.35 \\
\hline Total Cholesterol & 0.27 & 0.009 & -0.05 & 0.62 \\
\hline
\end{tabular}

MAP: Mean arterial pressure; TG: Triglycerides; CRF: Cardiorespiratory fitness; All analysis were adjusted for age, sex and height.

A

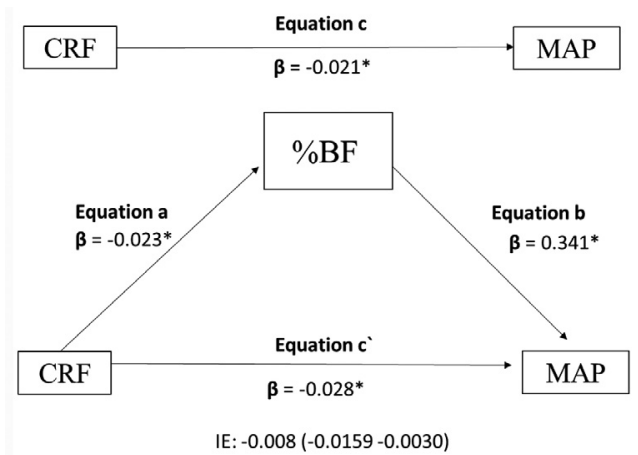

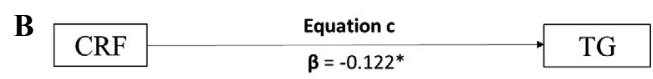

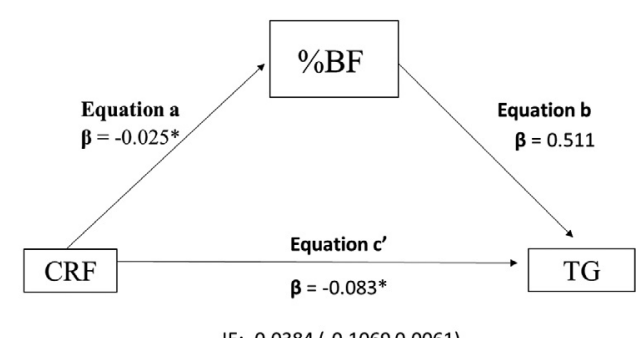

Figure 1. (A) Percentage of body fat mediation model of the relationship between cardiorespiratory fitness and mean arterial pressure; (B) Percentage of body fat mediation model of the relationship between cardiorespiratory fitness and triglycerides; CRF: Cardiorespiratory fitness; MAP: Mean arterial pressure; \%BF: Percentage of body fat; TG: Triglycerides. ${ }^{*} \mathrm{p}<0.001$. The analysis was adjusted for age, sex and height. 


\section{Discussion}

Our study shows that $\% \mathrm{BF}$ and $\mathrm{CRF}$ were associated with $\mathrm{TG}$ and MAP. Moreover, the mediation analyses disclosed that $\% \mathrm{BF}$ was a mediator in the relationship between CRF and MAP and the estimated percentage of total effect mediated by \%BF was $29 \%$. Our findings also showed a negative association between $\mathrm{CRF}$ and $\mathrm{TG}$, independent of \%BF.

Our data agree with a study developed with 7.821 children and adolescents indicated that $\% \mathrm{BF}$ were associated with total cholesterol, HDL and LDL cholesterol and triglycerides ${ }^{21}$. Data from Brazil showed that individual between the ages of 6 and 19 years with excess of body weight, elevated $\% \mathrm{BF}$ and waist circumference presented a positive correlation with alteration in the lipid profile ${ }^{22}$. Furthermore, Wheelock, Fufaa, Nelson, Hanson, Knowler, Sinha ${ }^{23}$ used BMI as an adiposity parameter and found that higher BMI was associated with blood pressure elevation and high TG levels in children and adolescents.

Likewise, our study found that CRF was associated with MAP and TG, which is in accordance with the previous study showing that the prevalence of dyslipidemia is directly related to both obesity and lower levels of $\mathrm{CRF}^{7}$. CRF was also associated with blood pressure in children ${ }^{24,25}$.

Therefore, CRF and adiposity are considered an important health indicator in children ${ }^{26}$. Indeed, previous studies have been demonstrated a relationship between CRF and adiposity with cardiovascular risk factor in children and adolescents ${ }^{5,27}$. However, it is not established which indicator, CRF or adiposity, is the most important for health and the link between both remain controversial, especially in the child population. Barry, Baruth, Beets, Durstine, Liu, Blair ${ }^{28}$ suggested that high levels of CRF could counteract the negative effects of obesity morbidity and mortality. Based on this assumption, obesity compared to CRF, would be the less preponderant factor for health than is widely believed. On the other hand, Buchan, Young, Boddy, Baker ${ }^{29}$ found that adiposity, evaluated through BMI and non-CRF were independently associated with cardiometabolic risk factors.

Our mediation analysis offers new information into understanding the relationship between adiposity, CRF and MAP, suggesting that $\% \mathrm{BF}$ parameter mediates the relationship between CRF and MAP. Thus, the effect of CRF on MAP seems to be minimized by the negative effect of body adiposity. These results were achieved after adjustment for sex, age and height and highlight that high CRF levels and a healthy body composition are important for maintaining adequate arterial blood pressure. Taking this aspect into consideration, physical activity program should be focused on reducing body fat and increasing CRF.

In accordance with our results, a study including 1.604 schoolchildren from Spain, indicated that adiposity assessed through BMI, mediates the relationship between CRF and $\mathrm{MAP}^{12}$. In the same line, Díez-Fernándes, Sanchez-Lopez, Mora-Rodriguez, Notario-Pacheco, Torrijos-Nino, MartinezVizcaino ${ }^{11}$ showed that BMI mediated the association between $\mathrm{CRF}$ and metabolic syndrome, including MAP, with a percentage of effect mediated by BMI of $16 \%$. Similar results were found in young Spanish adults in which different body composition variables such as BMI, waist circumference, fat mass percentage acted as mediators between CRF and blood pressure ${ }^{30}$. Likewise, in 935 Colombian children and adolescents, García-Hermoso, Agostinis-Sobrinho, Mota, Santos, Correa-Bautista, RamírezVélez ${ }^{31}$ showed that high levels of CRF might not counteract the negative consequences ascribed to adiposity on inflammation.

Thus, high blood pressure levels are related to low levels of CRF and adiposity ${ }^{12}$. Likely, the mechanisms involved in increased blood pressure are associated with the adipokines secreted by visceral adipocytes that have been linked to diminished insulinsensitivity ${ }^{32}$. Furthermore, the favorable impact of CRF on blood pressure is based on reduced sympathetic nervous system activity and improvement in endothelial function ${ }^{33}$.

Conversely, \%BF was not a mediator in the relationship between CRF and TG. Our finding indicates that there was a direct association between these variables, independent of $\% \mathrm{BF}$, suggesting the necessity of highlighted aerobic fitness as a health indicator. Indeed, studies have been shown that low CRF in children and adolescents is independently associated with cardiovascular risk factors, including $\mathrm{TG}^{34}$.

A study developed with adults indicated that changes over time in both adiposity and physical fitness predicted the development of cardiometabolic risk factors, such hypertension and dyslipidemia, but the impact of fitness appears somewhat better than did adiposity for future risk of this disorders ${ }^{35}$. In addition, increasing fitness was associated with reductions in all-cause of cardiovascular mortality, approximately $15 \%$. Regarding BMI changes, no associations were found $\mathrm{d}^{36}$. Thus, studies have indicated that a normal-weight is not synonymous with being healthy ${ }^{27}$.

Therefore, the relative and combined contribution of physical fitness and fatness to health in children are scarce. Considering that obesity is a major public health, and physical fitness is related to cardiometabolic risk, we highlight that lifestyle intervention programs should focus on reducing weight/fat, but also increasing CRF. Several studies suggest that intervention programs developed at school environment that address diverse components, such as physical activity and nutritional guidance, appear to be extremely effective for promoting an active and healthy lifestyle ${ }^{37,38}$, even $\mathrm{CRF}^{39}$. Thus, effort should be concentrated to sustain an effective physical education curriculum, aimed to health promotion, during the key period of children and adolescents, considering that choices made in this period of life tend to remain in adulthood.

Our study has some limitations. The analysis had a crosssectional design, so we cannot make cause-effect inferences, also the sample was selected by convenience. Furthermore, there are many factors that were not measured and influence cardiometabolic profile, especially in children, such as sexual maturity or diet. However, strengths of this study are the mediation analysis; one of the first studies that used this kind of analysis in Brazilian children; use of the gold standard to measure percentage of body fatness, while most studies considered BMI as an adiposity parameter. Our data add to previous findings reported in the literature and give additional strength towards the influence of \% $\mathrm{BF}$ in the association between $\mathrm{CRF}$ and cardiovascular risk factors in Brazilian children. Future studies should also considerate potential confounders, such as physical activity, 
sedentary habits and socioeconomic status to better explaining the role of $\% \mathrm{BF}$. In fact, cardiometabolic risk is a complex issue, related to lifestyle and genetic factors.

In conclusion, $\% \mathrm{BF}$ mediates the association between $\mathrm{CRF}$ and MAP. Our findings show that the importance of a healthy body composition for the prevention of high blood pressure levels in childhood as well as the relevance of physical activity on these parameters.

\section{References}

1. World Health Organization. All causes, age standardized mortality rate, both sexes. 2002.

2. Fobian AD, Elliott L, Louie T. A Systematic Review of Sleep, Hypertension, and Cardiovascular Risk in Children and Adolescents. Curr Hypertens Rep. 2018;20(42).

3. Andersen LB, Harro M, Sardinha LB, Froberg K, Ekelund U, Brage $\mathrm{S}$, et al. Physical activity and clustered cardiovascular risk in children: a cross-sectional study (The European Youth Heart Study). Lancet. 2006;368(9532):299-304.

4. Bugge A, El-Naaman B, Mcmurray RG, Froberg K, Andersen LB. Tracking of clustered cardiovascular disease risk factors from childhood to adolescence. Pediatr Res. 2013;73(2):245-9.

5. Ruiz JR, Cavero-Redondo I, Ortega FB, Welk GJ, Andersen LB, Martinez-Vizcaino V. Cardiorespiratory fitness cut points to avoid cardiovascular disease risk in children and adolescents; What level of fitness should raise a red flag? A systematic review and meta-analysis. Br J Sports Med. 2016;50(23):1451-8.

6. Ruiz JR, Castro-Piñero J, Artero EG, Ortega FB, Sjöström M, Suni J, et al. Predictive validity of health-related fitness in youth: a systematic review. Br J Sports Med. 2009;43(12):909-23.

7. Reuter CP, Silva PT da, Renner JDP, Mello ED de, Valim AR de M, Pasa L, et al. Dyslipidemia is Associated with Unfit and OverweightObese Children and Adolescents. Arq Bras Cardiol. 2016;188-93.

8. Ortega FB, Ruiz JR, Labayen I, Lavie CJ, Blair SN. The Fat but Fit paradox: what we know and don't know about it. Br J Sports Med. 2018;52(3):151-153.

9. Jago R, Drews KL, McMurray RG, Thompson D, Volpe SL, Moe EL, et al. Fatness, fitness, and cardiometabolic risk factors among sixth-grade youth. Med Sci Sports Exerc. 2010;42(8):1502-10.

10. Steele RM, Brage S, Corder K, Wareham NJ, Ekelund U. Physical activity, cardiorespiratory fitness, and the metabolic syndrome in youth. J Appl Physiol. 2008;105(1):342-51.

11. Diez-Fernandez A, Sanchez-Lopez M, Mora-Rodriguez R, NotarioPacheco B, Torrijos-Nino C, Martinez-Vizcaino V. Obesity as a mediator of the influence of cardiorespiratory fitness on cardiometabolic risk: a mediation analysis. Diabetes Care. 2014;37(3):855-62.

12. Pozuelo-Carrascosa DP, Sánchez-López M, Cavero-Redondo I, Torres-Costoso A, Bermejo-Cantarero A, Martínez-Vizcaíno V. Obesity as a Mediator between Cardiorespiratory Fitness and Blood Pressure in Preschoolers. J Pediatr. 2017;182.

13. Sardinha LB, Santos DA, Silva AM, Grøntved A, Andersen LB, Ekelund U. A Comparison between BMI, Waist Circumference, and Waist-To-Height Ratio for Identifying Cardio-Metabolic Risk in Children and Adolescents. PLoS One. 2016;11(2):e0149351.

14. Gaya ACA. Projeto Esporte Brasil Manual de testes e avaliação. 2015.
15. Bös K. Handbuch Motorische Tests. Hogrefe Ve. Göttingen; 2001.

16. Franklin SS, Lopez VA, Wong ND, Mitchell GF, Larson MG, Vasan RS, et al. Single versus combined blood pressure components and risk for cardiovascular disease: the Framingham Heart Study. Circulation 2009;119:243-50.

17. Drozdz D, Kwinta P, Korohoda P, Pietrzyk JA, Drozdz M, Sancewicz-Pach K. Correlation between fat mass and blood pressure in healthy children. Pediatr Nephrol. 2009; 24(9):1735-40.

18. Martın-Espinosa N, Díez-FernandezA, Sanchez-Lopez M, Merino AR, De La Cruz LL, Solera-Martınez M, et al. Prevalence of high blood pressure and association with obesity in Spanish schoolchildren aged 4-6 years old. Plos One. 2017. DOI:10.1371/journal.pone.0170926

19. Issa J, Strunz C, Giannini S. Precisão e exatidão das dosagens dos lípides sangüíneos em equipamento portátil (Cholestech-LDX). Arq Bras Cardiol. 1996;339-42.

20. Preacher KJ, Haye AF. Asymptotic and resampling strategies for assessing and comparing indirect effects in multiple mediator models. Behav Res Methods. 2008;40(3):879-891

21. Lamb M, Ogden C. Association of body fat percentage with lipid concentrations in children and adolescents : United States , 1999 - 2004. Am J Clin Nutr. 2011;1999-2004.

22. Ribas S a, Santana da Silva LC. Anthropometric indices: predictors of dyslipidemia in children and adolescents from north of Brazil. Nutr Hosp. 2012;27(4):1228-35.

23. Wheelock KM, Fufaa GD, Nelson RG, Hanson RL, Knowler WC, Sinha M. Cardiometabolic risk profile based on body mass index in American Indian children and adolescents. Pediatr Obes. 2017; 12(4):295-303.

24. Dencker M, Thorsson O, Karlsson MK, Linden C, Wollmer P, Andersen LB. Aerobic fitness related to cardiovascular risk factors in young children. Eur J Pediatr. 2012;171(4):705-10.

25. Anderssen SA, Cooper AR, Riddoch C, Sardinha LB, Harro M, Brage $\mathrm{S}$, et al. Low cardiorespiratory fitness is a strong predictor for clustering of cardiovascular disease risk factors in children independent of country, age and sex. Eur J Cardiovasc Prev Rehabil. 2007;14(4):526-31.

26. Ortega FB, Cadenas-Sánchez C, Sui X, Blair SN, Lavie CJ. Role of Fitness in the Metabolically Healthy but Obese Phenotype: A Review and Update. Prog Cardiovasc Dis. 2015;58(1):76-86.

27. Ortega FB, Lavie CJ, Blair SN. Obesity and cardiovascular disease. Circ Res. 2016;118(11):1752-70.

28. Barry VW, Baruth M, Beets MW, Durstine JL, Liu J, Blair SN. Fitness vs. fatness on all-cause mortality: A meta-analysis. Prog Cardiovasc Dis. 2014;56(4):382-90.

29. Buchan DS, Young JD, Boddy LM, Baker JS. Independent associations between cardiorespiratory fitness, waist circumference, BMI, and clustered cardiometabolic risk in adolescents. Am J Hum Biol. 2013;35:29-35.

30. Díez-Fernández A, Sánchez-López M, Nieto JA, González-García A, Miota-Ibarra J, Ortiz-Galeano I, et al. Relationship between cardiorespiratory fitness and blood pressure in young adults: A mediation analysis of body composition. Hypertens Res. 2017;40(5):511-5.

31. Garcia-Hermoso A, Agostinis-Sobrinho C, Mota J, Santos RM, Correa-Bautista JE, Ramírez-Vélez R. Adiposity as a full mediator of the influence of cardiorespiratory fitness and inflammation in schoolchildren: The FUPRECOL Study. Nutr Metab Cardiovasc Dis. 2017;27(6):525-33. 
32. Zachariah JP, Hwang S, Hamburg NM, Benjamin EJ, Larson MG, Levy D, et al. Circulating adipokines and vascular function: cross-sectional associations in a community-based cohort. Hypertension. 2016;67(2):294-300.

33. Dishman RK, Heath GW, Lee I-Min. Physical activity and hypertension. In Human Kinetics (eds), Physical Activity Epidemiology. Champaign, IL: Human Kinetics; 2nd edn, 2013, p 145-166.

34. Ruiz JR, Ortega FB, Rizzo NS, Villa I, Hurtig-Wennlof A, Oja L, et al. High cardiovascular fitness is associated with low metabolic risk score in children: the European Youth Heart Study. Pediatr Res. 2007;61(3):350-5.

35. Lee DC, Sui X, Church TS, Lavie CJ, Jackson AS, Blair SN. Changes in fitness and fatness on the development of cardiovascular disease risk factors: Hypertension, metabolic syndrome, and hypercholesterolemia. J Am Coll Cardiol. 2012;59(7):665-72.

36. Lee D -c., Sui X, Artero EG, Lee I-M, Church TS, McAuley PA, et al. Long-Term Effects of Changes in Cardiorespiratory Fitness and Body Mass Index on All-Cause and Cardiovascular Disease Mortality in Men: The Aerobics Center Longitudinal Study. Circulation. 2011;124(23):2483-90.

37. Jussila A-M, Vasankari T, Paronen O, Sievanen H, Tokola K, Vaha-Ypya H, et al. KIDS OUT! Protocol of a brief school-based intervention to promote physical activity and to reduce screen time in a sub-cohort of Finnish eighth graders. BMC Public Health. 2015;15(1):634.

38. Mura G, Rocha NBF, Helmich I, Budde H, Machado S, Wegner $\mathrm{M}$, et al. Physical activity interventions in schools for improving lifestyle in European countries. Clin Pract Epidemiol Ment Health. 2015;11:77-101.
39. Pozuelo-Carrascosa DP, García-Hermoso A, Álvarez-Bueno C, Sánchez-López M, Martinez-Vizcaino V. Effectiveness of schoolbased physical activity programmes on cardiorespiratory fitness in children: a meta-analysis of randomised controlled trials. Br J Sports Med. 2017.

\section{Acknowledgement}

National Council for Scientific and Technological Development, process number 401969/2016-9/ Universal Announcement.

This work was supported by CAPES (Coordination for the Improvement of Higher Level).

\section{Corresponding author}

Caroline Brand

Street: Felizardo, 750. Neighborhood: Jardim botânico, 90690-200 City: Porto Alegre, Brazil.

E-mail: carolbrand@hotmail.com.br

Manuscript received on June 8, 2018

Manuscript accepted on August 13, 2018

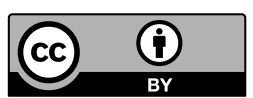

Motriz. The Journal of Physical Education. UNESP. Rio Claro, SP, Brazil - eISSN: 1980-6574 - under a license Creative Commons - Version 3.0 